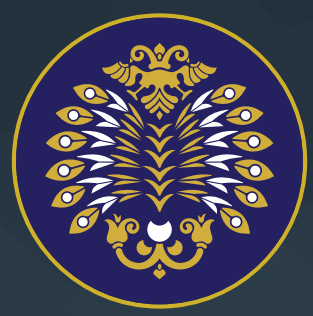

\title{
The Eurasian
}

Journal of Medicine

Official Journal of Atatürk University School of Medicine

\section{ORIGINAL ARTICLES}

\section{Early Orthopedic Rehabilitation in CRPS-1}

Fatih Baygutalp, Ayhan Kul

Protective Effect of Udenafil Against Ischemia Reperfusion Injury

Zulfu Sertkaya, Orhan Koca, Metin Ozturk, Mehmet Akyuz, Gulistan Gumrukcu, Musab Ali Kutluhan,

Muhammet Ihsan Karaman

\section{Elderly Empowerment Scale: Validity and Reliability}

Parinaz Jahanpeyma, Emine Karaman, Yasemin Yildirim, Sevnaz Sahin, Fisun Senuzun Aykar

\section{Bronchial Artery Embolization in Tuberculosis}

Orkun Sarioglu, Ahmet Ergin Capar, Melike Yuksel Yavuz, Umit Belet

Occupational Risk for Crimean-Congo Hemorrhagic Fever Infection

Hakan Aydin, Muhammet Hamidullah Uyanik, Murat Karamese, Ibrahim Sozdutmaz,

Mehmet Ozkan Timurkan, Abdulkadir Gulen, Erkan Ozmen, Osman Aktas

\section{Epistaxis and Anatomical Variations}

Ismail Salcan, Abdulkerim Olgun

\section{Social Media Disorder and Ostracism}

Gul Ergun, Ali Alkan

Histological Comparison of Nanocomposite Multilayer Biomimetic Scaffold Kazim Solak, Istemi Yucel, Z. Okan Karaduman, Sena Arda, M. Mufit Orak, Ahmet Midi 


\title{
The Eurasian \\ Journal of Medicine
}

Official Journal of Atatürk University School of Medicine

\section{Volume: 52 Issue: 2 June 2020}

\author{
Editor in Chief \\ Metin Akgün \\ Department of Pulmonary Diseases, Atatürk University \\ School of Medicine, Erzurum, Turkey
}

\section{Section Editors}

\author{
Internal Medicine \\ Hakan Döneray \\ Department of Pediatrics, Atatürk University \\ School of Medicine, Erzurum, Turkey
}

\author{
Surgical Sciences \\ Şenol Adanur \\ Department of Urology, Atatürk University \\ School of Medicine, Erzurum, Turkey
}

\author{
Basic Sciences \\ Osman Aktaş \\ Department of Medical Microbiology, Atatürk \\ University School of Medicine, Erzurum, Turkey
}

\author{
Biostatistical Editor \\ Kamber Kaşali \\ Department of Biostatistics, Atatürk University \\ School of Medicine, Erzurum, Turkey
}

\author{
Production Coordinator \\ Ömer Araz \\ Department of Pulmonary Diseases, Atatürk University \\ School of Medicine, Erzurum, Turkey
}

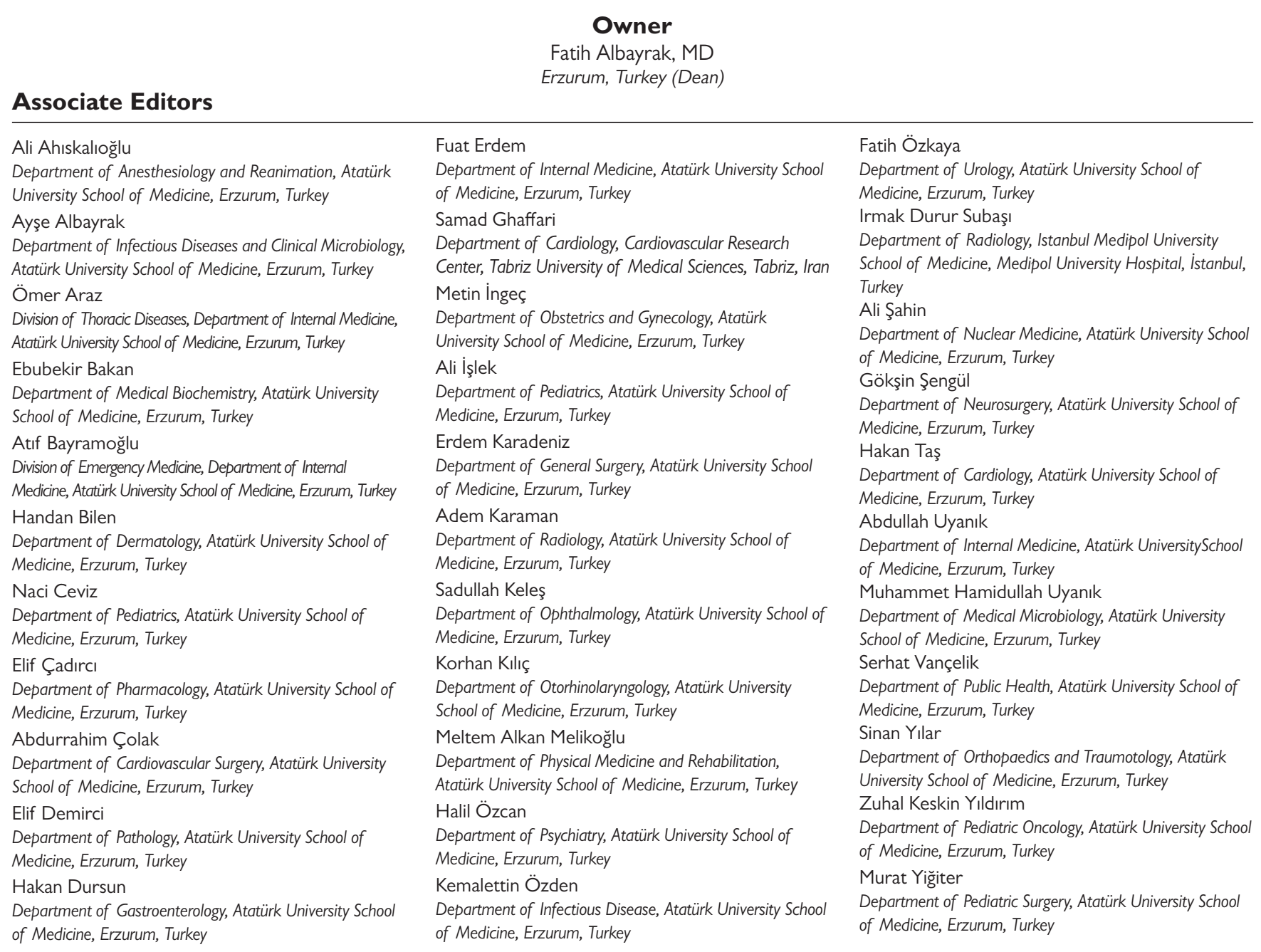




\section{The Eurasian \\ Journal of Medicine}

Official Journal of Atatürk University School of Medicine

Volume: 52 Issue: 2 June 2020

\section{International Advisory Board}

\section{Fatih Albayrak}

Department of Gastroenterology, Erzurum Region Training

and Research Hospital, Erzurum, Turkey

Fatih Alper

Department of Radiology, Ataturk University Aziziye

Training and Research Hospital, Erzurum, Turkey

Sabri Selçuk Atamanalp

Department of General Surgery, Atatürk University School

of Medicine, Erzurum, Turkey

Sara Bright

UCL Institute for Women's Health, Maternal \& Fetal

Medicine, Perinatal Brain Repair Group, London, United

Kingdom

Şükrü Emre

Department of Gastroenterology and Hepatology, Yale

New Haven Transplantation Center, Connecticut, USA

Mustafa Gül

Department of Physiology, Atatürk University School of

Medicine, Erzurum, Turkey

Fuat Gündoğdu

Department of Cardiology, Atatürk University School of

Medicine, Erzurum, Turkey

Serge Gauthier

Alzheimer Disease Research Unit, The Douglas Research Centre, Montreal, Canada
Harry K. Genant

Professor Emeritus, Department of Radiology, University of California San Francisco, USA

Alin Lucian Girnita

Department of General Surgery, University of Cincinnati, Ohio, USA

Ahmet Hacımüftüoğlu

Department of Pharmacology, Atatürk University School of Medicine, Erzurum, Turkey

Ted Hadfield

Department of Infectious Diseases and Pathology,

University of Florida, Emerging Pathogens Institute, Florida, USA

Zekai Halıcı

Department of Pharmacology, Atatürk University School of Medicine, Erzurum, Turkey

Hakan Hadi Kadıoğlu

Department of Neurosurgery, Atatürk University School of Medicine, Erzurum, Turkey

Sami Gökhan Kılıç

Department of Gynecology, University of Texas at Austin, Texas, USA

Sunjoo Kim

Department of Surgery, Sungkyunkwan University, Seoul, Korea
Ata Mahmoodpoor

Department of Anesthesiology, Critical Care Medicine, Tabriz University of Medical Sciences, Tabriz, Iran

Zerrin Orbak

Department of Pediatrics, Atatürk University School of

Medicine, Erzurum, Turkey

Aytekin Oto

Department of Radiology and Surgery, UChicago

Medicine, Illinois, USA

İsa Özbey

Department of Urology, Atatürk University School of

Medicine, Erzurum, Turkey

Zülal Özkurt

Department of Infectious Diseases, Atatürk University School of Medicine, Erzurum, Turkey

Süreyya Savaşan

Department of Pediatric Hematology and Oncology,

Children's Hospital of Michigan, Michigan, USA

Luca Semerano

Department of Rheumatology, Hôpitaux de Paris | AP-HP, Paris, France

Nihal Tümer

Department of Pharmacology and Therapeutics, University of Florida, Florida, USA

Şebnem Ünlü

Department of Microbiology and Molecular Genetics,

University of Pittsburgh, Pennsylvania, USA
/AVES Publishe

Ibrahim KARA

Publication Director

Ali ŞAHIN

Editorial Development Gizem KAYAN TEKAYÜT

Deputy Publications Director Gökhan ÇiMEN
Publication Coordinators Irem SOYSAL

Arzu YILDIRIM

Deniz KAYA

Gülnur MERCAN

Bahar ALBAYRAK

Finance and Administration Zeynep YAKIŞIRER ÜREN Betül ÇIMEN
Project Coordinators

Sinem KOZ

Doğan ORUÇ

Graphics Department

Ünal ÖZER

Deniz DURAN

Beyzanur KARABULUT
Contact:

Address: Büyükdere Cad. 105/9 34394 Mecidiyeköy, Şişli, İstanbul, TURKEY

Phone: +90212 217 1700

Fax: +902122172292

E-mail: info@avesyayincilik.com 


\section{The Eurasian \\ Journal of Medicine}

Official Journal of Atatürk University School of Medicine

\section{Aims and Scope}

Eurasian Journal of Medicine (Eurasian J Med) is an international, scientific, open access periodical published by independent, unbiased, and tripleblinded peer-review principles. The journal is the official publication of Atatürk University School of Medicine and published triannually in February, June, and October. The publication language of the journal is English.

The aim of the Eurasian Journal of Medicine is to publish original research papers of the highest scientific and clinical value in all medical fields. The Eurasian J Med also includes reviews, editorial short notes and letters to the editor that either as a comment related to recently published articles in our journal or as a case report.

The target audience of the journal includes researchers, physicians and healthcare professionals who are interested or working in in all medical disciplines.

The editorial and publication processes of the journal are shaped in accordance with the guidelines of the International Committee of Medical Journal Editors (ICMJE), World Association of Medical Editors (WAME), Council of Science Editors (CSE), Committee on Publication Ethics (COPE), European Association of Science Editors (EASE), and National Information Standards Organization (NISO). The journal is in conformity with the Principles of Transparency and Best Practice in Scholarly Publishing (doaj.org/bestpractice).

Eurasian Journal of Medicine is indexed in PubMed Central, Web of Science - Emerging Sources Citation Index, TUBITAK ULAKBIM TR Index, Scopus, DOAJ, EBSCO, CINAHL, ProQuest, Gale, and CAS.
Processing and publication are free of charge with the Journal. No fees are requested from the authors at any point throughout the evaluation and publication process. All manuscripts must be submitted via the online submission system, which is available at http://www.eajm.org. The journal guidelines, technical information, and the required forms are available on the Journal's web page.

All expenses of the Journal are covered by the Atatürk University School of Medicine. Potential advertisers should contact the Editorial Office. Advertisement images are published only upon the Editor-in-Chief's approval.

Statements or opinions expressed in the manuscripts published in the Journal reflect the views of the author(s) and not the opinions of the Atatürk University School of Medicine, editors, editorial board, and/ or publisher; the editors, editorial board, and publisher disclaim any responsibility or liability for such materials.

Eurasian Journal of Medicine is an open access publication and the Journal's publication model is based on Budapest Open Access Initiative (BOAI) declaration. Journal's archive is available online, free of charge at http://www.eajm.org. Eurasian Journal of Medicine's content is licensed under a Creative Commons Attribution 4.0 International License.

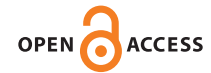




\section{The Eurasian \\ Journal of Medicine}

Official Journal of Atatürk University School of Medicine

\section{Instructions for Authors}

\section{CONTEXT}

Eurasian Journal of Medicine (Eurasian J Med) is an international, scientific, open access periodical published by independent, unbiased, and triple-blinded peer-review principles. The journal is the official publication of Atatürk University School of Medicine and published triannually in February, June, and October. The publication language of the journal is English.

The aim of the Eurasian J Med is to publish original research papers of the highest scientific and clinical value in all medical fields. The Eurasian J Med also includes reviews, editorial short notes and letters to the editor that either as a comment related to recently published articles in our journal or as a case report.

The target audience of the journal includes researchers, physicians and healthcare professionals who are interested or working in in all medical disciplines.

\section{EDITORIAL AND PUBLICATION PROCESS}

The editorial and publication processes of the journal are shaped in accordance with the guidelines of the International Council of Medical Journal Editors (ICMJE), the World Association of Medical Editors (WAME), the Council of Science Editors (CSE), the Committee on Publication Ethics (COPE), the European Association of Science Editors (EASE), and National Information Standards Organization (NISO). The journal conforms to the Principles of Transparency and Best Practice in Scholarly Publishing (doaj.org/bestpractice).

Originality, high scientific quality, and citation potential are the most important criteria for a manuscript to be accepted for publication. Manuscripts submitted for evaluation should not have been previously presented or already published in an electronic or printed medium. The journal should be informed of manuscripts that have been submitted to another journal for evaluation and rejected for publication. The submission of previous reviewer reports will expedite the evaluation process. Manuscripts that have been presented in a meeting should be submitted with detailed information on the organization, including the name, date, and location of the organization.

\section{PEER REVIEW PROCESS}

Manuscripts submitted to Eurasian Journal of Medicine will go through a triple-blind peer-review process. Each submission will be reviewed by at least two external, independent peer reviewers who are experts in their fields in order to ensure an unbiased evaluation process. The editorial board will invite an external and independent editor to manage the evaluation processes of manuscripts submitted by editors or by the editorial board members of the journal. The Editor in Chief is the final authority in the decision-making process for all submissions.

\section{ETHICAL PROCEDURES}

An approval of research protocols by the Ethics Committee in accordance with international agreements (World Medical Association Declaration of Helsinki "Ethical Principles for Medical Research Involving Human Subjects," amended in October 2013, www.wma.net) is required for experimental, clinical, and drug studies and for some case reports. If required, ethics committee reports or an equivalent official document will be requested from the authors. For manuscripts concerning experimental research on humans, a statement should be included that shows that written informed consent of patients and volunteers was obtained following a detailed explanation of the procedures that they may undergo. For studies carried out on animals, the measures taken to prevent pain and suffering of the animals should be stated clearly. Information on patient consent, the name of the ethics committee, and the ethics committee approval number should also be stated in the Materials and Methods section of the manuscript. It is the authors' responsibility to protect the patients' anonymity carefully.
For photographs that may reveal the identity of the patients, signed releases of the patient or their legal representative should be enclosed, and the publication approval must be provided in the Materials and Methods section.

\section{PLAGIARISM}

Eurasian Journal of Medicine is extremely sensitive about plagiarism. All submissions are screened by a similarity detection software (iThenticate by CrossCheck) at any point during the peer-review and/or production process. Even if you are the author of the phrases or sentences, the text should not have unacceptable similarity with the previously published data.

When you are discussing others' (or your own) previous work, please make sure that you cite the material correctly in every instance.

In the event of alleged or suspected research misconduct, e.g., plagiarism, citation manipulation, and data falsification/fabrication, the Editorial Board will follow and act following COPE guidelines.

\section{AUTHORSHIP}

Each person listed as an author should fulfill the authorship criteria recommended by the International Committee of Medical Journal Editors (ICMJE - www.icmje.org). The ICMJE recommends that authorship is based on the following four criteria:

I. Substantial contributions to the conception or design of the work; or the acquisition, analysis, or interpretation of data for the work; AND

2. Drafting the work or revising it critically for important intellectual content; AND

3. Final approval of the version to be published; AND

4. Agreement to be accountable for all aspects of the work in ensuring that questions related to the accuracy or integrity of any part of the work are appropriately investigated and resolved.

In addition to being accountable for the parts of the work he/she has done, an author should be able to identify which co-authors are responsible for specific other parts of the work. Also, authors should have confidence in the integrity of the contributions of their co-authors.

All those designated as authors should meet all four criteria for authorship, and all who meet the four criteria should be identified as authors. Those who do not meet all four criteria should be acknowledged in the title page of the manuscript.

Eurasian Journal of Medicine requires corresponding authors to submit a signed and scanned version of the authorship contribution form (available for download through http://www.eajm.org) during the initial submission process to act appropriately on authorship rights and to prevent ghost or honorary authorship. If the editorial board suspects a case of "gift authorship," the submission will be rejected without further review. As part of the submission of the manuscript, the corresponding author should also send a short statement declaring that he/she accepts to undertake all the responsibility for authorship during the submission and review stages of the manuscript.

\section{DECLARATION OF INTEREST}

Eurasian Journal of Medicine requires and encourages the authors and the individuals involved in the evaluation process of submitted manuscripts to disclose any existing or potential conflicts of interests, including financial, consultant, and institutional, that might lead to potential bias or a conflict of interest. Any financial grants or other support received for a submitted study from individuals or institutions should be disclosed to the Editorial Board. To disclose a potential conflict of interest, the ICMJE Potential Conflict of Interest Disclosure Form should be filled in and submitted by all contributing 


\section{The Eurasian \\ Journal of Medicine}

Official Journal of Atatürk University School of Medicine

authors. The journal's Editorial Board resolves cases of a potential conflict of interest of the editors, authors, or reviewers within the scope of COPE and ICMJE guidelines.

The Editorial Board of the journal handles all appeal and complaint cases within the scope of COPE guidelines. In such cases, authors should get in direct contact with the editorial office regarding their appeals and complaints. When needed, an ombudsperson may be assigned to resolve claims that cannot be resolved internally. The Editor in Chief is the final authority in the decision-making process for all appeals and complaints.

\section{COPYRIGHT AND LICENSE}

Eurasian Journal of Medicine requires each submission to be accompanied by a Copyright Agreement and Acknowledgement of Authorship Form (available for download http://www.eajm.org). When using previously published content, including figures, tables, or any other material in both print and electronic formats, authors must obtain permission from the copyright holder. Legal, financial and criminal liabilities in this regard belong to the author(s). By signing the this form authors retain copyright of their work and agree that the article, if accepted for publication by the Eurasian Journal of Medicine will be licensed under a Creative Commons Attribution 4.0 International License (CC BY).

\section{DISCLAIMER}

Statements or opinions expressed in the manuscripts published in Eurasian Journal of Medicine reflect the views of the author(s) and not the opinions of the editors, the editorial board, or the publisher; the editors, the editorial board, and the publisher disclaim any responsibility or liability for such materials. The final responsibility regarding the published content rests with the authors.

\section{MANUSCRIPT PREPARATION}

The manuscripts should be prepared in accordance with ICMJE-Recommendations for the Conduct, Reporting, Editing, and Publication of Scholarly Work in Medical Journals (updated in December 2019 - http://www.icmje.org/icmje-recommendations.pdf). Authors are required to prepare manuscripts in accordance with the CONSORT guidelines for randomized research studies, STROBE guidelines for observational original research studies, STARD guidelines for studies on diagnostic accuracy, PRISMA guidelines for systematic reviews and meta-analysis, ARRIVE guidelines for experimental animal studies, and TREND guidelines for non-randomized public behavior.

Manuscripts can only be submitted through the journal's online manuscript submission and evaluation system, available at http://www.eajm.org. Manuscripts submitted via any other medium and submissions by anyone other than one of the authors will not be evaluated.

Manuscripts submitted to the journal will first go through a technical evaluation process where the editorial office staff will ensure that the manuscript has been prepared and submitted in accordance with the journal's guidelines. Submissions that do not conform to the journal's guidelines will be returned to the submitting author with technical correction requests.

Authors are required to submit the following:

- Copyright Agreement and Acknowledgement of Authorship Form and

- ICMJE Potential Conflict of Interest Disclosure Form (should be filled in by all contributing authors) during the initial submission. These forms are available for download at http://www.eajm.org.

\section{Preparation of the Manuscript}

Title page: A separate title page should be submitted with all submissions and this page should include:
- The full title of the manuscript as well as a short title (running head) of no more than 50 characters,

- Name(s), affiliations, highest academic degree(s), and ORCID IDs of the author(s),

- Grant information and detailed information on the other sources of support,

- Name, address, telephone (including the mobile phone number), and email address of the corresponding author,

- Acknowledgment of the individuals who contributed to the preparation of the manuscript but who do not fulfill the authorship criteria.

Abstract: An abstract should be submitted with all submissions except for Letters to the Editor. The abstract of Original Articles should be structured with subheadings (Objective, Materials and Methods, Results, and Conclusion). Please check Table I below for word count specifications.

Keywords: Each submission must be accompanied by a minimum of three to a maximum of six keywords for subject indexing at the end of the abstract. The keywords should be listed in full without abbreviations. The keywords should be selected from the National Library of Medicine, Medical Subject Headings database (https://www. nlm.nih.gov/mesh/MBrowser.html).

\section{Manuscript Types}

Original Articles: This is the most important type of article since it provides new information based on original research. The main text of original articles should be structured with Introduction, Materials and Methods, Results, and Discussion subheadings. Please check Table I for the limitations for Original Articles.

Statistical analysis to support conclusions is usually necessary. Statistical analyses must be conducted in accordance with international statistical reporting standards (Altman DG, Gore SM, Gardner MJ, Pocock SJ. Statistical guidelines for contributors to medical journals. Br Med J 1983: 7; I489-93). Information on statistical analyses should be provided with a separate subheading under the Materials and Methods section and the statistical software that was used during the process must be specified.

Units should be prepared in accordance with the International System of Units (SI).

Review Articles: Reviews prepared by authors who have extensive knowledge on a particular field and whose scientific background has been translated into a high volume of publications with a high citation potential are welcomed. These authors may even be invited by the journal. Reviews should describe, discuss, and evaluate the current level of knowledge of a topic in clinical practice and should guide future studies. The main text should contain Introduction, Clinical and Research Consequences, and Conclusion sections. Please check Table I for the limitations for Review Articles.

Letters to the Editor: Two types of letter are welcome. One is comment on a recently published article in our journal and the other one is case report. The comments should be written in a logical way to discuss important parts, overlooked aspects or lacking part of the paper. As a case report we only accept for publication the reports on rare cases or conditions that constitute challenges in diagnosis and treatment, those offering new therapies or revealing knowledge not included in the literature, and interesting and educative cases. The text for case reports should include Introduction, Case Report, and Discussion, subheadings. Please check Table I for the limitations for Letter to Editor.

\section{Tables}

Tables should be included in the main document, presented after the reference list, and they should be numbered consecutively in the order they are referred to within the main text. A descriptive title must be placed above the tables. Abbreviations used in the tables should be defined below the tables by footnotes (even if they are defined within 


\section{The Eurasian \\ Journal of Medicine}

Official Journal of Atatürk University School of Medicine

Table 1. Limitations for each manuscript type

Type of manuscript

Word limit

Abstract word limit

Reference limit Table limit

Figure limit

Original Article

3500

250 (Structured)

35

6

3 (max. 4 images of each)

Review Article

5000

250

75

6

6 (max. 4 images of each)

Letter to the Editor

Comment

No abstract

5

200 (structured)

15

No table

No media

Case Report

2

2 figures (max. 4 images of each)

the main text). Tables should be created using the "insert table" command of the word processing software and they should be arranged clearly to provide easy reading. Data presented in the tables should not be a repetition of the data presented within the main text but should be supporting the main text.

\section{Figures and Figure Legends}

Figures, graphics, and photographs should be submitted as separate files (in TIFF or JPEG format) through the submission system. The files should not be embedded in a Word document or the main document. When there are figure subunits, the subunits should not be merged to form a single image. Each subunit should be submitted separately through the submission system. Images should not be labeled (a, b, c, etc.) to indicate figure subunits. Thick and thin arrows, arrowheads, stars, asterisks, and similar marks can be used on the images to support figure legends. Like the rest of the submission, the figures too should be blind. Any information within the images that may indicate an individual or institution should be blinded. The minimum resolution of each submitted figure should be $300 \mathrm{DPI}$. To prevent delays in the evaluation process, all submitted figures should be clear in resolution and large in size (minimum dimensions: $100 \times 100 \mathrm{~mm}$ ). Figure legends should be listed at the end of the main document.

All acronyms and abbreviations used in the manuscript should be defined at first use, both in the abstract and in the main text. The abbreviation should be provided in parentheses following the definition.

When a drug, product, hardware, or software program is mentioned within the main text, product information, including the name of the product, the producer of the product, and city and the country of the company (including the state if in USA), should be provided in parentheses in the following format: "Discovery St PET/CT scanner (General Electric, Milwaukee, WI, USA)"

All references, tables, and figures should be referred to within the main text, and they should be numbered consecutively in the order they are referred to within the main text.

Limitations, drawbacks, and the shortcomings of original articles should be mentioned in the Discussion section before the conclusion paragraph.

\section{Digital Image Guide}

The Eurasian J Med requires that all digital artwork be prepared according to professional standards. Digital files must meet the Journal requirements to be accepted for publication.

Files that do not meet the guidelines will be rejected. Please refer to the instructions below when preparing images for publication.
A. Image Preparation Checklist. To verify that you have fulfilled the requirements for electronic image preparation, use the following checklist. Each category is expanded below the checklist (Table 3).

- Black-and-white images are saved in grayscale mode (not black and white).

- Photographic images are saved in RGB color mode (not CMYK or indexed color).

- Files are submitted in native TIFF or EPS and are not embedded in another program such as Microsoft Word, PowerPoint, or Excel.

- Charts or illustrations created in Microsoft Office (Word, PowerPoint, Excel) are submitted in native format and do not include embedded images.

- Charts created in SPSS, SigmaPlot or ChemDraw are submitted as EPS images.

- All graphics are sized to $100 \%$ of their print dimensions so that no scaling is necessary (3.2" wide for I-column figures and 6.4" wide for 2-column figures).

- Images have been scanned according to our scanning guidelines.

- Files are named using our recommended naming conventions.

B. Color. When preparing digital images for publication, it is important to scan and save the electronic files in the correct color space.

I. Photographic images. Images such as photographs, angiograms, echocardiograms, etc., should be scanned and saved in RGB color mode, even if the images will be printed in grayscale. (The journal compositors will convert these images to their final grayscale or CMYK color modes.) Note: Printing in color is expensive and is not always necessary. Please inform the Journal editors if an image requires color for clarity.

2. Line art. Black-and-white images, including line drawings, charts, graphs, and ECG and EEG tracings, should be scanned and saved in grayscale mode (not black-and white or color). (For charts created in SPSS, refer to Section C.2 on creating EPS file formats. For charts and graphs created in Microsoft Office, refer to Section C.3.)

3. Avoid ICC Profiles. Images should not contain any ICC profiles.

C. File Format. Submit only TIFF or EPS for electronic images. See instructions for submitting artwork that was created in Microsoft Office programs (Word, PowerPoint, Excel).

I. TIFF (Tagged Image File Format). TIFF is recommended for photographic images. When preparing TIFF images, be sure to refer to our scanning guidelines for the proper resolution. Note: The Journal accepts TIFF images that are saved with LZW compression; choosing this option will result in smaller files. In most software programs, a TIFF is made by choosing File/Save as... or Export/TIFF or TIF. For more information, consult the Help menu of your software.

2. EPS (Encapsulated Postscript). EPS is recommended for line art, charts, and illustrations that are created using professional drawing programs such as Adobe 


\section{The Eurasian \\ Journal of Medicine}

Official Journal of Atatürk University School of Medicine

Illustrator, SPSS, ChemDraw, CorelDraw, SigmaPlot, etc. When submitting EPS files for publication, be sure to use the following guidelines:

- Convert text to outlines or include/embed fonts. Use only Journal-approved fonts.

- Flatten any layers.

- Use line weights greater than 0.5 points.

- Include an 8-bit preview/header at a resolution of $72 \mathrm{dpi}$.

- Save color images in RGB color mode.

In most drawing programs, an EPS file is made by choosing File/Save as ... or Export/ EPS. For more information, consult the Help menu of your software.

3. Microsoft Office (Word, Excel, PowerPoint). Charts and illustrations created in any Microsoft Office programs are accepted. Do not submit Microsoft Office files that contain embedded images. When creating charts and illustrations, use the following guidelines:

- Work in black and white, not color.

- Do not use patterns for fill color; use black, white, and shades of gray.

- Avoid 3-dimensional charts.

- Use only Journal-approved fonts.

- Use line weights greater than 0.5 points.

- Submit the grouped image so that the Journal compositors can access the datasheet.

\section{AVOID THE FOLLOWING:}

- Submitting graphics that are downloaded or saved from Web pages. The resolution will be too low, regardless of how the image looks on screen.

- Submitting GIF files. GIF files are never appropriate for publication. Scanning preprinted photographs (already published halftones). The printing process introduces distortion into the photograph that will transfer to the scan.

- Generating TIFFs within the Microsoft Office Document

- Scanning Program. This proprietary program changes the image formatting in such a way that the image cannot be opened in our image evaluation program.

\section{Resolution and Scanning}

I. Images must be scanned at the proper resolution to ensure print quality. Use the following guidelines to select the correct scanning resolution. Images that are scanned at lower resolutions will be rejected.

- Photographic images without text or arrows: 300 dpi/ppi

- Photographic images with text or arrows: 600 dpi/ppi

- Black-and-white line art: 1200 dpi/ppi

a. Scanning photographic images without text or arrows

- Scan in RGB mode.

- Scan at $300 \mathrm{dpi} / \mathrm{ppi}$.

- Select a target width of $7.5 \mathrm{~cm}$ for I-column figures and $15.5 \mathrm{~cm}$ for 2-column figures.

- Crop images tightly; do not scan the margins.

- Use the Eurasian J Med naming convention; save as a TIFF and apply LZW compression.

b. Scanning photographic images with text or arrows

- Scan in RGB mode.

- Scan at $600 \mathrm{dpi} /$ ppi (even if text or labels will be added after the image is scanned).

- Select a target width of $7.5 \mathrm{~cm}$ for I-column figures or $15.5 \mathrm{~cm}$ for 2-column figures.

- Crop images tightly; do not scan the margins.

- If adding labels, use an approved font. If the labels are pixilated, you may be asked for an unlabeled version.

\begin{tabular}{|l|l|l|}
\hline Type & Format/Color Mode/Resolution \\
\hline $\begin{array}{l}\text { Photographic } \\
\text { images without } \\
\text { text or arrows }\end{array}$ & $\begin{array}{l}\text { TIFF/RBG/300 } \\
\text { dpi-ppi }\end{array}$ \\
\hline $\begin{array}{l}\text { Photographic } \\
\text { images with } \\
\text { text or arrows }\end{array}$ & $\begin{array}{l}\text { TIFF/RBG/600 } \\
\text { dpi-ppi }\end{array}$ \\
\hline $\begin{array}{l}\text { Black-and-white } \\
\text { line art }\end{array}$ & $\begin{array}{l}\text { PIFF/Grayscale/ } \\
\text { Black-and-white } \\
\text { chart or graph } \\
\text { from Microsoft } \\
\text { Office program }\end{array}$ \\
\hline $\begin{array}{l}\text { Black-and-white } \\
\text { line art from } \\
\text { a professional } \\
\text { drawing program } \\
\text { such as Adobe } \\
\text { Illustrator }\end{array}$
\end{tabular}

- Use the Eurasian J Med naming convention; save as a TIFF and apply LZW compression.

c. Scanning black-and-white line art

- Scan in grayscale mode.

- Scan at $1200 \mathrm{dpi} / \mathrm{ppi}$.

- Select a target width of $7.5 \mathrm{~cm}$ " for I-column figures and $15.5 \mathrm{~cm}$ " for 2-column figures.

- Images should be tightly cropped; do not scan the margins.

- If adding labels, use an approved font. If the labels are pixilated, you may be asked for an unlabeled version.

- Use the Eurasian J Med naming convention; save as a TIFF and apply LZW compression.

\section{Scanning originals that are smaller than the target width}

- Choose the correct color space for the photographic image or line art.

- Determine the correct resolution. If an image has a width smaller than the target width, it is necessary to compensate by increasing the scanning resolution. To increase the resolution, divide the actual width by the target width (either $7.5 \mathrm{~cm}$ 


\section{The Eurasian \\ Journal of Medicine}

Official Journal of Atatürk University School of Medicine

or $15.5 \mathrm{~cm}$ ). Multiply the answer by the target dpi and round up to the nearest hundred. The result will determine the scanning dpi. Use the following example: If an image is 2.4" wide and needs to be $300 \mathrm{dpi} /$ ppi at 3" wide, then 3 divided by 2.4 $=1.251 .25,1.25$ times $300=375$, and round up to 400 . Thus, if the 2.4 " image is scanned at $400 \mathrm{dpi} / \mathrm{ppi}$, the Journal can properly convert the image to be 3 " wide at 300 dpi.

- Use the Eurasian J Med naming convention and save.

\section{E. Naming Files}

I. Naming convention. Please use the following naming convention for electronic images:

Author last name + figure number.file format

For example: Okurl.eps or OkurlA.tif

2. Revising images. Any time that you revise an image and resubmit it to the Journal, you need to add a version number to ensure that the image will be re-evaluated.

For example: Smithl.eps would be saved the next time as Smith I_v2.eps

Note: Always allow the software program to add the file format extension. Files that do not contain an extension will be rejected. To change a file format extension, you must use a software program; renaming a file extension does not properly convert a file. For example, simply renaming the JPG extension as TIFF does not convert the file to a TIFF image. Opening a JPG file in Photoshop (or in a comparable software program) and saving as a TIFF does properly convert the file.

Note: You can safely change the author last name + figure number (i.e., anything before the "dot-file format" portion) by using the Rename command.

F. Approved Fonts. Please use one of the following fonts for text in labels, graphs, and charts:

- Adobe Garamond

- Arial

- Helvetica

- Symbol

- Times New Roman

- Univers LT

\section{G. Labels}

I. Do not place figure labels (A, B, C, etc.) on the digital images; include the letter in the figure file name (for example, Smith2B.tif).

2. If images are part of an A, B, C series, scan and submit each image separately.

$\mathrm{H}$. How to Submit Images. To submit digital artwork, refer to the information in the Manuscript Submission section.

\section{References}

Both in-text citations and the references must be prepared according to the Vancouver style.

While citing publications, preference should be given to the latest, most up-to-date publications. Authors are responsible for the accuracy of references If an ahead-ofprint publication is cited, the DOI number should be provided. Journal titles should be abbreviated in accordance with the journal abbreviations in Index Medicus/ MEDLINE/ PubMed. When there are six or fewer authors, all authors should be listed. If there are seven or more authors, the first three authors should be listed followed by "et al." In the main text of the manuscript, references should be cited using Arabic numbers in parentheses. The reference styles for different types of publications are presented in the following examples.
Journal Article: Ahn SS, Kim Y], Hur J, et al. Preparing first-year radiology residents and assessing their readiness for on-call responsibilities: results over 5 years. AJR Am J Roentgenol 2009; 192: 539-44.

Book Section: Suh KN, Keystone JS. Malaria and babesiosis. Gorbach SL, Barlett JG, Blacklow NR, editors. Infectious Diseases. Philadelphia: Lippincott Williams; 2004.p.2290-308.

Books with a Single Author: Sweetman SC. Martindale the Complete Drug Reference. 34th ed. London: Pharmaceutical Press; 2005.

Editor(s) as Author: Huizing EH, de Groot JAM, editors. Functional reconstructive nasal surgery. Stuttgart-New York: Thieme; 2003.

Conference Proceedings: Bengisson S. Sothemin BG. Enforcement of data protection, privacy and security in medical informatics. In: Lun KC, Degoulet P, Piemme TE, Rienhoff O, editors. MEDINFO 92. Proceedings of the 7th World Congress on Medical Informatics; 1992 Sept 6- I0; Geneva, Switzerland. Amsterdam: North-Holland; 1992. pp. I56I-5.

Scientific or Technical Report: Cusick M, Chew EY, Hoogwerf B, Agrón E, Wu L, Lindley A, et al. Early Treatment Diabetic Retinopathy Study Research Group. Risk factors for renal replacement therapy in the Early Treatment Diabetic Retinopathy Study (ETDRS), Early Treatment Diabetic Retinopathy Study Kidney Int: 2004. Report No: 26.

Thesis: Yılmaz B. Ankara Üniversitesindeki Öğrencilerin Beslenme Durumları, Fiziksel Aktiviteleri ve Beden Kitle İndeksleri Kan Lipidleri Arasındaki llişkiler. H.Ü. Sağılık Bilimleri Enstitüsü, Doktora Tezi. 2007.

Manuscripts Accepted for Publication, Not Published Yet: Slots J. The microflora of black stain on human primary teeth. Scand J Dent Res. 1974.

Epub Ahead of Print Articles: Cai L, Yeh BM, Westphalen AC, Roberts JP, Wang ZJ. Adult living donor liver imaging. Diagn Interv Radiol. 2016 Feb 24. doi: I0.5I52/ dir.2016.15323. [Epub ahead of print].

Manuscripts Published in Electronic Format: Morse SS. Factors in the emergence of infectious diseases. Emerg Infect Dis (serial online) 1995 Jan-Mar (cited 1996 June 5): I(I): (24 screens). Available from: URL: http:/ www.cdc.gov/ncidodIEID/cid. htm.

\section{REVISIONS}

When submitting a revised version of a paper, the author must submit a detailed "Response to the reviewers" that states point by point how each issue raised by the reviewers has been covered and where it can be found (each reviewer's comment, followed by the author's reply and line numbers where the changes have been made) as well as an annotated copy of the main document. Revised manuscripts must be submitted within 30 days from the date of the decision letter. If the revised version of the manuscript is not submitted within the allocated time, the revision option may be canceled. If the submitting author(s) believe that additional time is required, they should request this extension before the initial 30-day period is over.

Accepted manuscripts are copy-edited for grammar, punctuation, and format. Once the publication process of a manuscript is completed, it is published online on the journal's webpage as an ahead-of-print publication before it is included in its scheduled issue. A PDF proof of the accepted manuscript is sent to the corresponding author and their publication approval is requested within 2 days of their receipt of the proof. 


\section{The Eurasian \\ Journal of Medicine}

Official Journal of Atatürk University School of Medicine

\section{Editorials}

106 Coronavirus (COVID-19) Pandemic and Radical Cystectomy Senol Adanur, Salih Al, Ozkan Polat

108|Report on Advances for General Medicine in 2019: Neurosurgery, Urology, Gynecology and Obstetrics, and Internal Medicine

Hakan Doneray

\section{Original Articles}

110

Effect of Early Orthopedic Rehabilitation on Development of Complex Regional Pain Syndrome Type I

Fatih Baygutalp, Ayhan Kul

115

Protective Effect of Udenafil Against Ischemia Reperfusion Injury Due to Testicular Torsion/Detorsion in Rat Model Zulfu Sertkaya, Orhan Koca, Metin Ozturk, Mehmet Akyuz, Gulistan Gumrukcu, Musab Ali Kutluhan, Muhammet Ihsan Karaman

120 Adaptation of Diabetic Empowerment Scale-Short Form to Older Individuals and to Turkish Language: Validity and Reliability Study

Parinaz Jahanpeyma, Emine Karaman, Yasemin Yildirim, Sevnaz Sahin, Fisun Senuzun Aykar

126|Angiographic Findings and Outcomes of Bronchial Artery Embolization in Patients with Pulmonary Tuberculosis Orkun Sarioglu, Ahmet Ergin Capar, Melike Yuksel Yavuz, Umit Belet

132 Serological Investigation of Occupational Exposure to Zoonotic Crimean-Congo Hemorrhagic Fever Infection Hakan Aydin, Muhammet Hamidullah Uyanik, Murat Karamese, Ibrahim Sozdutmaz, Mehmet Ozkan Timurkan, Abdulkadir Gulen, Erkan Ozmen, Osman Aktas

136 Is There a Relationship Between Epitaxis and Anatomical Variations?

Ismail Salcan, Abdulkerim Olgun

139 The Social Media Disorder and Ostracism in Adolescents: (OSTRACA- SM Study)

Gul Ergun, Ali Alkan

145 Histological Comparison of Nanocomposite Multilayer Biomimetic Scaffold, A Chondral Scaffold, and Microfracture Technique to Repair Experimental Osteochondral Defects in Rats

Kazim Solak, Istemi Yucel, Z. Okan Karaduman, Sena Arda, M. Mufit Orak, Ahmet Midi
153 Developing an Online Portal for Determining the Genomic Signature of Archaic DNA that are Associated to Modern Human Genetic Diseases: A Meta-Analysis Study

Niyazi Senturk, Mahmut Cerkez Ergoren

161 Paraoxonase Activity and Phenotype Distribution in Patients with Chronic Obstructive Pulmonary Disease

Nurhan Sarioglu, Cigdem Bilen, Celalettin Cevik, Nahit Gencer

166 Comparison of Functional Capacity and Symptoms of COPD Patients with and without Pulmonary Hypertension Fikriye Kalkan, Elif Yilmazel Ucar, Kamuran Kalkan, Omer Araz

171 Is Ebselen A Therapeutic Target in Fracture Healing? Ahmet Kose, Duygu Kose, Zekai Halici, Ali Aydin, Naci Ezirmik, Orhan Karsan, Erdem Toktay

176 Auditory Function of Patients with Obstructive Sleep Apnea Syndrome: A Study

Mustafa Sitki Gozeler, Furkan Sengoz

180 Retrospective Analysis of I 20 Cases of latrogenic and Traumatic Peripheral Arterial Pseudoaneurysms Yavuzer Koza, Ugur Kaya

185 Determination of Endothelial Nitric Oxide Synthase Gene Polymorphism and Plasma Asymmetric Dimethyl Arginine Concentrations in Patients with Lung Cancer

Zafer Bayraktutan, Ahmet Kiziltunc, Ebubekir Bakan, Hamit Hakan Alp

\section{Reviews}

191 Unclear Issues Regarding COVID-19

Aycan Yuksel, Dilek Karadogan, Canan Gunduz Gurkan, Fatma Tokgoz Akyil, Zehra Nur Toreyin, Feride Marim, Huseyin Arikan, Tugba Sismanlar Eyuboglu, Nagehan Emiralioglu, Irem Serifoglu, Elif Develi, Selman Celik, Umran Ozden Sertcelik, Tugba Ramasli Gursoy, Mehmet Fatih Elversli, Asli Oncel, Berrin Er, Ali Firincioglulari, Fatma Esra Gunaydin, Hilal Ozakinci, Neslihan Ozcelik, Dorina Esendagli, Asena Aydin, Neslihan Kose, Merve Ercelik, Pinar Yildiz Gulhan, Ethem Yildiz, llim Irmak, Bilge Yilmaz Kara, Selcuk Gurz, Fatma Gulsum Karakas, Metin Akgun

197|Coronavirus Infection Prevention by Wearing Masks Thi Sinh Vo, Tran Thi Thu Ngoc Vo, Tran Thi Bich Chau Vo

202 Lessons Learned so Far from the Pandemic: A Review on Pregnants and Neonates with COVID- 19

Feride Marim, Dilek Karadogan, Tugba Sismanlar Eyuboglu, Nagehan Emiralioglu, Canan Gunduz Gurkan, Zehra Nur Toreyin, Fatma Tokgoz Akyil, Aycan Yuksel, Huseyin Arikan, Irem Serifoglu, Tugba Ramasli Gursoy, Abdulsamet Sandal, Metin Akgun 


\section{The Eurasian \\ Journal of Medicine}

Official Journal of Atatürk University School of Medicine

211 Neuraxial and Perineural Bleeding after Neuraxial Techniques: An Overview of the Last Year

Alessandro De Cassai, Christelle Correale, Ludovica Sandei

\section{Perspective}

217 Social Causes of Vaccine Rejection-Vaccine Indecision Attitudes in the Context of Criticisms of Modernity Ali Ergur

\section{Letters to the Editor}

224 Atypical Presentation of COVID- 19: Acute Renal Failure

Bugra Kerget, Metin Akgun, Nazim Dogan

Comment on "The Clinical Importance of the Plasma
227 Atherogenic Index, Other Lipid Indexes, and Urinary Sodium and Potassium Excretion in Patients with Stroke"

Erkan Cure, Medine Cumhur Cure

229|Nablus Mask-Like Facial Syndrome with Moderate Developmental Delay

Bahadir Turan, Mehmet Akif Akinci, Ibrahim Selcuk Esin, Onur Burak Dursun

\section{$231 \mid$ Erratum}

